\title{
Percepção de professores sobre a educação inclusiva em uma instituição de nível superior no semiárido paraibano
}

\author{
Perception of teachers on inclusive education in a higher education institution in the semi-arid \\ region of Paraíba
}

\author{
E. P. O. Almeida ${ }^{1}$; J. L. S. Oliveira ${ }^{2}$; C. A. A. Sousa ${ }^{3}$; T. M. M. Santos ${ }^{2} ;$ E. \\ Silva ${ }^{1,2}$ \\ ${ }^{1}$ Unidade Acadêmica de Ciências Biológicas/Centro de Saúde e Tecnologia Rural, Universidade Federal de \\ Campina Grande, CEP 58708-110, Patos-PB, Brasil \\ ${ }^{2}$ Programa de Pós-Graduação em Desenvolvimento e Meio Ambiente/Centro de Ciências Exatas e da Natureza,
Universidade Federal de Campina Grande, CEP 58051-970, João Pessoa-PB, Brasil
}

${ }^{3}$ Programa de Pós-Graduação em Horticultura Tropical/Centro de Ciências e Tecnologia Agroalimentar, Universidade Federal de Campina Grande, CEP 58840-000, Pombal-PB, Brasil

\author{
*elzenirpereira@bol.com.br
}

(Recebido em 03 de agosto de 2018; aceito em 15 de janeiro de 2019)

\begin{abstract}
O objetivo deste estudo foi conhecer a percepção de professores de uma instituição de nível superior no semiárido paraibano sobre a Educação Inclusiva. Para a coleta de dados, foram aplicados questionários a professores do ensino superior com 10 questões/afirmativas, distribuídas em discursivas (6) e objetivas na escala de Likert (4). Esse método permite descobrir graus de opinião que podem fazer a diferença para entender o feedback recebido e foi aplicado com cinco níveis de resposta. O número amostral foi de 27 professores entrevistados que lecionam disciplinas em cursos diversos. Os dados reportaram que os professores lecionam a alunos com Necessidades Educacionais Especiais com deficiências intelectuais, tais como autismo $(11,7 \%)$ e déficit de aprendizagem $(7,4 \%)$, e que buscam formas de inclusão desses alunos por meio de metodologias diferenciadas, durante o ensino das disciplinas, tendo como objetivo de superar as limitações dos alunos. 74,0\% $(\mathrm{n}=20)$ dos professores nunca visitou instituições que atendam apenas alunos com Necessidades Educacionais Especiais e o mesmo percentual nunca participou de nenhuma capacitação para trabalhar com alunos que possuam essas necessidades. $14,8 \%(\mathrm{n}=4)$ dos professores discordaram que podem ter em algum momento alguma deficiência. A percepção sobre a importância da inclusão de alunos com Necessidades Educacionais Especiais no nível superior deve estar presente desde a formação inicial do professor. A capacitação profissional do docente irá minimizar as dificuldades encontradas por esses alunos em questão após ingressar na universidade, evitando assim a evasão dos mesmos.
\end{abstract}

Palavras-chave: Inclusão Social, Exclusão social, Educação Inclusiva, Professores, Likert.

The objective of this study was to know the perception of teachers of a higher education institution in the semi-arid region of Paraíba, on Inclusive Education. For the data collection, questionnaires were applied to teachers of higher education with 10 questions/affirmations, distributed in discourse (6) and objective in the Likert scale (4), this method allows to discover degrees of opinion that can make the difference to understand the received feedback, has been applied with five levels of response. The sample number was 27 teachers interviewed who teach subjects in different courses. The data reported that teachers teach students with special educational needs with intellectual disabilities, such as autism (11.7\%) and learning deficits (7.4\%), who seek ways of through differentiated methodologies, during the teaching of the subjects, in order to overcome the limitations of the students. $74.0 \%(n=20)$ of teachers never visited institutions that only serve students with, and the same percentage never participated in any training to work with students who have these needs. $14.8 \%(n=4)$ of teachers disagreed that they may have some deficiency at some point. The perception about the importance of the inclusion of pupils with at the higher level must be present from the initial formation of the teacher. The professional qualification of the teacher, will minimize the difficulties encountered by these students in question with after joining the university, thus avoiding evasion of the same.

Keywords: Social Inclusion, Social Exclusion, Inclusive Education, Teachers, Likert. 


\section{INTRODUÇÃO}

Historicamente, alunos com Necessidades Educacionais Especiais (NEE) enfrentaram problemas que limitavam sua inserção e aceitação em ambientes de formação na educação formal [1]. Esse modo de pensar vem sendo superado por consequência da necessidade que os alunos têm de ter seu espaço nos ambientes educacionais com respeito às suas necessidades [2]. Na escola, considera-se que existe a inclusão quando os alunos, apesar de suas limitações, conseguem se envolver e participar de forma ativa das atividades desenvolvidas [3]. Todavia, quando não existe a acessibilidade, ou a carência desta, a inclusão dos alunos é comprometida [2].

No ensino superior, diferentes problemas relacionados a inclusão de alunos com NEE especiais podem ser identificados sendo, mais frequente, o despreparo das instituições em atender de forma satisfatória a diversidade de necessidades especiais que podem existir [4].

Os processos seletivos tradicionais também podem ser caracterizados como entraves que impedem ou dificultam o ingresso de alunos com NEE no ensino superior, motivando o interesse dos alunos apenas em cursos que possam atender especificamente algumas dessas necessidades, como o curso de libras para pessoas surdas [5]. Embora existam muitas limitações na inclusão de alunos com NEE no ensino superior, a má gestão, a carência de acessibilidade e de profissionais capacitados nas universidades públicas ou particulares são as causas mais frequentes.

$\mathrm{O}$ professor como mediador dos processos de aprendizagem pode contribuir para que a receptividade de alunos com NEE em sala, por outros alunos, possa ser maior e, consequentemente, a convivência e produtividade em sala terão melhores resultados [6]. Assim, é importante que o professor possa estar em constante aprendizado e capacitação para que atenda as demandas da educação especial, mas, também, é necessário destacar a importância da formação inicial desses profissionais, pois nesse momento muitas dificuldades podem surgir ao iniciar o exercício da profissão [7].

Tais pressupostos são importantes para atender melhor às necessidades da inclusão. Considerando que cada professor pode trabalhar de forma diferente em resposta as condições de trabalho ou ao tipo de necessidade especial que o aluno possui, pode existir, por parte do professor, uma receptividade melhor para lidar com deficiências físicas em relação a distúrbios de comportamento, por exemplo [6].

Além disso, outro fator importante que nem sempre é considerado na formação dos professores são os aspectos emocionais, tal aspecto é indispensável na formação docente [1], considerando que, a partir dele, o professor pode se sensibilizar com as NEE presentes em sala colaborando para melhorar a relação entre professor e aluno. O objetivo deste trabalho foi conhecer a percepção de professores de uma instituição de nível superior no semiárido paraibano, sobre a educação inclusiva.

\section{MATERIAL E MÉTODOS}

Foram aplicados questionários a professores de uma instituição particular de nível superior, intitulada de "Faculdades Integradas de Patos" que está localizada dentro do semiárido paraibano, no município de Patos, Paraíba (Figura 1). A instituição possui atualmente 18 cursos de formação profissional em diversas áreas do conhecimento. 


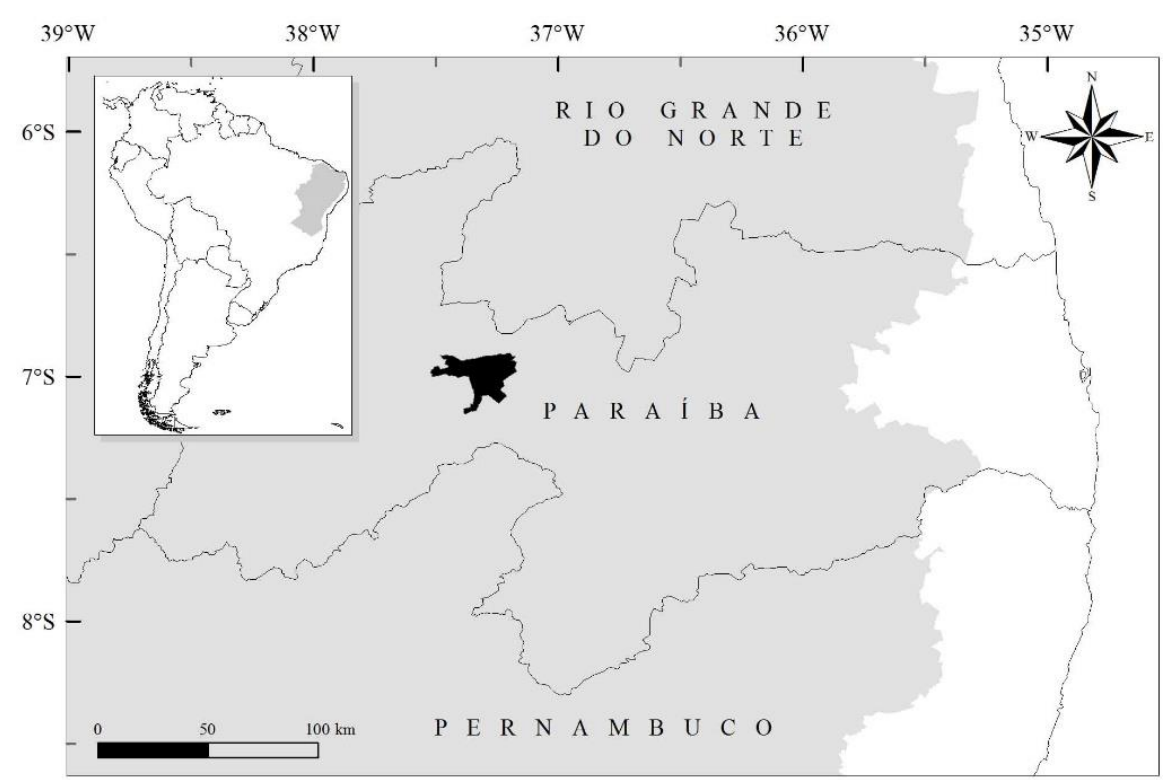

Figura 1: Localização do município de Patos (em preto), Paraíba, com destaque (em cinza) para a região semiárida. Fonte: Os autores (2018).

O questionário aplicado conteve 10 questões distribuídas entre questões abertas (6) e questões objetivas (4), construídas no modelo de Likert, com 5 níveis de resposta (de discordo totalmente à concordo totalmente) (Tabela 1). As questões envolveram temas relacionados à Educação Inclusiva na percepção de professores de nível superior, sendo entrevistados, no total, 27 professores de diversas áreas do conhecimento. Esta pesquisa foi aprovada pelo Comitê de Ética em Pesquisa das Faculdades Integradas de Patos (CEP/FIP) sob o protocolo $\mathrm{N}^{\circ}$ CAAE: 94846518.7.0000.5181.

Tabela 1: Questões aplicadas a professores de uma instituição intitulada "Faculdades Integradas de Patos" de nível superior no semiárido paraibano sobre aspectos relacionados a Educação Inclusiva.

2. Você possui alunos com Necessidades Educacionais Especiais? Se sim, quantos são e quais as deficiências?

3. Se a resposta anterior for sim, qual a capacitação (ou mudança didática) que você buscou para atender ao aluno?

4. Você conhece (visitou) uma instituição que atende exclusivamente alunos com Necessidades Educacionais Especiais? Por que? Se sim, como foi essa vivência?

5. Quais cursos de capacitação você já fez relacionados à Educação Especial?

6. Cite e conceitue as deficiências intelectuais que você já estudou e conhece.

\section{Afirmativas em Likert}

7. Me preocupo em buscar capacitação para o ensino adequado de alunos com Necessidades Educacionais Especiais.

8. Não parei ainda para observar se a faculdade que ensino teria acessibilidade para os deficientes visual e auditivo.

9. Se hoje eu recebesse um aluno com Necessidade Educacional Especial em minha aula eu saberia como recepciona-lo didaticamente.

10.Já tive a percepção que eu posso, a qualquer momento, ter uma deficiência intelectual e/ou física e, também necessitar de atendimento especial.

Fonte: Os autores (2018).

Os dados foram analisados por meio de estatística descritiva utilizando o software Microsoft Excel 2016 para as questões objetivas no modelo da escala de Likert. Para as análises qualitativas 
das questões discursivas, as respostas foram agrupadas em tendências de respostas de acordo com o tema estudado [8].

\title{
3. RESULTADOS E DISCUSSÃO
}

Os professores entrevistados, em sua maioria $(70,4 \% ; \mathrm{n}=19)$, apresentaram idades entre $31 \mathrm{e}$ 43 anos, sendo $81,5 \%$ do gênero feminino $(n=22)$ e $18,5 \%$ do gênero masculino $(n=5)$ e $55,6 \%$ $(\mathrm{n}=15)$ trabalham na instituição há mais de 5 anos.

Do total de entrevistados, 37,0\% ( $n=10)$ possuíam título de Mestre e 3,7\% ( $n=1)$ de Doutor. Os demais entrevistados eram graduados e possuíam pós-graduação latu-sensu. Parte dos professores entrevistados lecionam disciplinas em cursos na área da saúde $(48,1 \% ; \mathrm{n}=13)$, humanas (direito; $14,8 \% ; \mathrm{n}=4$ ) ou arquitetura $(7,4 \% ; \mathrm{n}=2)$.

Os professores $(44,4 \% ; n=12)$ tiveram uma percepção ampliada sobre o que seria a Educação Inclusiva, definindo-a como uma educação que promove a inclusão de todos aqueles que integram o meio social, independente de gênero, cor ou condição financeira. Entretanto, 33,4\% (n = 9) associou essa definição a inclusão de alunos com NEE, 14,8\% $(n=4)$ ou ao acolhimento e harmonização com empoderamento de pessoas excluídas socialmente. Apenas 7,4\% $(\mathrm{n}=2)$ não responderam a essa pergunta.

Muitos professores apresentaram limitações na compreensão da Educação Inclusiva no que propõe seu objetivo, que não remete apenas a inclusão de alunos com NEE, mas sim de igualdade no direito à educação. As limitações na percepção de alguns professores entrevistados no que se refere a compreensão da Educação Inclusiva podem estar relacionados a própria formação do professor, ao âmbito de trabalho e condições sociais e profissionais na qual estão inseridos, influenciando diretamente na obtenção de uma compreensão mais ampliada sobre a temática.

Em concordância com essa ideia, a Política Nacional de Educação Especial na Perspectiva da Educação Inclusiva afirma que:

\begin{abstract}
A educação inclusiva constitui um paradigma educacional fundamentado na concepção de direitos humanos, que conjuga igualdade e diferença como valores indissociáveis, e que avança em relação à ideia de equidade formal. Ao reconhecer que as dificuldades enfrentadas nos sistemas de ensino evidenciam a necessidade de confrontar as práticas discriminatórias e criar alternativas para superá-las [9] (p. 5).
\end{abstract}

Alguns autores destacam ainda que trabalhar a Educação Inclusiva em ambientes de formação é um exercício que se caracteriza também como desafio na sociedade contemporânea neste século e, para isso, é necessário o comprometimento com trabalhos interdisciplinares de diferentes áreas [10].

Em pesquisa similar, foi percebido que dentre 18 professores entrevistados em uma universidade no estado de São Paulo, apenas 2 deles souberam citar legislações e documentos que versem sobre a Educação Inclusiva [11]. Esse cenário, especialmente na universidade, pode explicar a dificuldade que os professores têm em buscar mecanismos para atender alunos com NEE, que pode ser proveniente da falta de conhecimento ou capacitação na área gerando limitações. Além disso, outra pesquisa reporta que os professores de escola pública entrevistados sentiram dificuldades de trabalhar a Educação Especial, destacando a principal limitação a prática pedagógica por estarem iniciando a carreira docente [7].

Poucos alunos possuem NEE na percepção dos professores $(26,0 \% ; n=7)$. De acordo com a percepção destes, as NEE mais citadas foram autismo $(11,7 \%)$ e déficit de aprendizagem $(7,4 \%)$, embora exista alunos com dislexia (3,7\%), Síndrome de Down $(3,7 \%)$, problemas de visão $(3,7 \%)$, e transtorno do déficit de atenção com hiperatividade (TDAH) $(3,7 \%)$. Os demais professores não citaram nenhuma deficiência.

Embora $66,7 \%(\mathrm{n}=18)$ dos professores não tenham respondido ao questionamento aplicado durante a entrevista sobre a capacitação ou mudança didática que buscam para atender ao aluno com NEE, dentre os professores que responderam a essa pergunta $(n=9), 14,8 \%(n=4)$ disseram buscar novas metodológicas didáticas para trabalhar com os alunos (Tabela 2). 
Tabela 2: Frequência (\%) de respostas dos professores do ensino superior no semiárido paraibano que buscam mudanças metodológicas e capacitação profissional para atender alunos com NEE.

\begin{tabular}{lr}
\hline Resposta dos professores entrevistados $(\mathrm{n}=9)$ & \multicolumn{1}{c}{$\%$} \\
\hline Metodologias mais didáticas & 14,8 \\
Capacitação com cursos de formação complementar & 11,1 \\
Atendimento individualizado e/ou diferenciado ao aluno & 3,7 \\
Não buscou nenhuma mudança na metodologia ou capacitação & 3,7 \\
\hline
\end{tabular}

Fonte: Autores, 2018.

O professor tem papel fundamental na inclusão dos alunos com NEE e, mesmo diante dessa importância, foi percebido que poucos professores buscaram mudar o método de ensino tradicional com alunos que possuem essas NEE, demonstrando a importância da sensibilização desses docentes para obter mais envolvimento em métodos alternativos de ensino que favoreçam a inclusão.

A busca por metodologias alternativas de ensino é importante para promover um melhor envolvimento dos alunos no âmbito da sala de aula, assim como favorecer o aumento no rendimento dos alunos em relação a aprendizagem, melhorando a qualidade do ensino e formação. Nessa discussão, é importante destacar que a inclusão se inicia em processos de mudanças ocorridas no interior dos indivíduos participantes do processo de educação, como autoridades, instituições, profissionais ou pessoas comuns que integram o cotidiano e que contribuem para a aceitação das diferenças [10].

Essa linha de discussão é também necessária por que muito se discute sobre como conseguir êxito na proposta de inserção da Educação Inclusiva, entretanto muitas são as divergências de quais caminhos podem ser adequados e eficientes no processo de inclusão [4].

Outros pesquisadores verificaram que dentre 62 dissertações pesquisadas entre os anos de 2010 a 2014, considerando pesquisas que envolveram a Educação Especial na perspectiva da surdez, a inserção dos surdos foi citada como necessária em diferentes ambientes, como no ensino regular inclusivo (20 dissertações), classe específica para surdos (18 dissertações) ou educação bilíngue (16) [12].

A maior parte dos entrevistados $(74,0 \% ; \mathrm{n}=20)$ nunca visitou instituições que atendessem exclusivamente alunos com NEE e 7,4\% $(\mathrm{n}=2)$ responderam que sim, porém não esclareceram como. Alguns professores $(18,6 \% ; \mathrm{n}=5)$ responderam positivamente a essa respectiva questão e relataram de forma simplificada como ocorreu essa experiência (Tabela 3 ).

Tabela 3: Experiências de professores de uma instituição de nível superior no semiárido paraibano após visita em instituições que atendem alunos com NEE.

\section{Respostas}

P 15 Sim. Durante as ações do mestrado em uma atividade prática de uma disciplina. Foi uma experiência muito produtiva, possível de compreender não apenas as limitações, mas também as potencialidades de cada um.

P 19 Sim. Fiz o curso de LIBRAS na FUNAD em João Pessoa. Local especializado no atendimento de pessoas com necessidades especiais diversas. Tive a oportunidade de participar de eventos junto a ASDEF (associação de deficientes), em João Pessoa, onde também prestam cursos e assistência apenas a pessoas com necessidades especiais.

P 20 Sim. Instituto dos Cegos em João Pessoa. Experiência singular e impactante

P 22 Sim, a APAE. Foi muito enriquecedora e gratificante. As pessoas especiais nos ensinam bastante, principalmente a valorizar cada momento e cada vivência.

P 25 Sim. Foi interessante, tivemos a oportunidade de vivenciarmos outra realidade.

Legenda: P - professor. Fonte: Autores, 2018.

Embora poucos professores tenham conhecido pessoalmente instituições que atendam exclusivamente alunos com NEE, as respostas evidenciam que essa vivência enriqueceu a prática docente. A vivência dos professores nesses ambientes é importante, considerando que por meio 
delas eles podem se motivar para a inclusão de alunos. Mesmo com a importância dos ambientes que atendem apenas alunos com NEE, o objetivo principal desses espaços era trabalhar as limitações dos alunos para que eles pudessem seguir sua formação em ambientes normais de ensino, em contrapartida, houve ao longo do tempo, a exclusão das pessoas nesses ambientes [13]. O professor na atualidade é desafiado a lidar com diferentes situações no âmbito da sua profissão, que exigem além do domínio de conteúdo, a capacidade de acompanhar as demandas da profissão [14]. Por isso, devem existir ambientes educacionais que se adequem para a inclusão de alunos na estrutura física e os professores também devem acompanhar essas mudanças por meio de qualificação profissional [15].

Os professores $(59,2 \% ; \mathrm{n}=16)$ citaram diferentes exemplos de deficiências intelectuais conhecidas, mas não as conceituaram. Dentre os professores que conceituaram, citaram como exemplos o autismo, Síndrome de Down e dislexia (Tabela 4), 14,8\% $(\mathrm{n}=4)$ não souberam citar nenhuma deficiência e $11,2 \%(n=3)$ não responderam.

Tabela 4: Conceitos de deficiências intelectuais na percepção de professores $(n=4)$ de uma instituição de nível superior no semiárido paraibano.

\begin{tabular}{|c|c|}
\hline & Respostas \\
\hline P 8 & Autismo: indivíduos que têm dificuldades de sociabilização, linguagem e comunicação. \\
\hline P 9 & $\begin{array}{l}\text { Síndrome de Down: Doença genética do cromossomo } 21 \text { que causa atrasos de } \\
\text { desenvolvimento e intelectuais. }\end{array}$ \\
\hline P 12 & $\begin{array}{l}\text { Dislexia que é um transtorno de aprendizagem onde os portadores apresentam: } \\
\text { desatenção, lentidão da aprendizagem da leitura, dificuldade de interpretação, entre } \\
\text { outros. }\end{array}$ \\
\hline P 1 & $\begin{array}{l}\text { Deficiência intelectual é um transtorno de desenvolvimento que faz o indivíduo } \\
\text { apresentar dificuldades em relação ao nível cognitivo e comportamental. Exemplo: } \\
\text { síndrome de Down e autismo. }\end{array}$ \\
\hline
\end{tabular}

Legenda: P - professor. Fonte: Autores, 2018.

Saber a definição e os tipos de deficiências intelectuais são importantes e esses dados remetem a uma preocupação emergente na Educação Inclusiva. Considera-se que, no ensino superior, grande parte das deficiências intelectuais podem não ser percebidas nem mesmo pelos alunos que a tem, como a dislexia, que pode ser descoberta quando conteúdos são ministrados pelo professor ou por meio do rendimento do aluno [4].

Alguns pesquisadores reportaram que metade das professoras entrevistadas relataram não ter suporte de profissionais que pudessem ajudar a compreender melhor os tipos de deficiências dos alunos em uma perspectiva mais aprofundada e, assim, poder melhorar e adequar as metodologias de ensino de acordo com as necessidades da turma [16]. Ainda nessa discussão, outros pesquisadores relatam que o professor deve se adequar as demandas da turma que leciona, ensinando a todos os alunos com respeito e responsabilidade com as necessidades que cada aluno pode ter [11].

Embora a capacitação docente seja essencial no ensino a alunos com NEE, 77,8\% $(n=21)$ dos entrevistados nunca participou de nenhum tipo de capacitação relacionada a Educação Especial. Dentre os que já participaram, citaram cursos de libras $(3,7 \% ; n=1)$, braille $(3,7 \% ; n=1)$, metodologias de ensino para autistas $(3,7 \% ; n=1)$, transtorno do espectro autista $(3,7 \% ; n=1)$ e palestras ou discussões em eventos $(7,4 \% ; \mathrm{n}=2)$.

A maioria dos professores $(88,9 \% ; \mathrm{n}=24)$ concordam em algum nível que buscam se capacitar para o ensino a alunos com NEE e muitos professores $(40,7 \% ; n=11)$ concordam que não observaram se o ambiente de trabalho tem acessibilidade para deficientes visuais e auditivos. Além disso, 18,5\% $(n=5)$ discorda que saberia receber um aluno com NEE e 14,8\% $(n=4)$ também discordam que pode ter alguma deficiência em algum momento (Tabela 5).

Apesar de os professores terem respondido, em sua maioria, de forma positiva, é possível perceber que alguns professores ainda não sabem ou saberiam lidar com alunos com NEE em sua turma e que também não refletiram em algum momento que também podem ter deficiências.

Em cursos de nível superior, foi identificado que durante um intervalo de 10 anos, apenas 3 disciplinas que abordassem temáticas envolvendo a Educação Inclusiva foram desenvolvidas em 
uma universidade no Mato Grosso do Sul [5]. Assim, futuros professores podem tornar-se profissionais sem ter tido a oportunidade de conhecimento sobre a Educação Especial.

Tabela 5: Frequência (\%) de respostas sobre aspectos relacionados a Educação Especial na percepção de professores de uma instituição de nível superior no semiárido paraibano.

\begin{tabular}{|c|c|c|c|c|c|}
\hline Afirmativas & 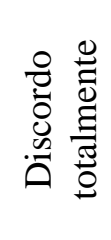 & 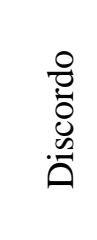 & $\begin{array}{ll}0 & 0 \\
0 & 0 \\
0 & 0 \\
0 & 0 \\
.0 & 0 \\
: 0 & 0 \\
\tilde{E} & 0 \\
\overline{0} & 0\end{array}$ & $\begin{array}{l}0 \\
0 \\
0 \\
0 \\
0 \\
0\end{array}$ & 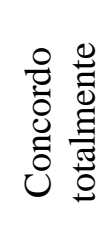 \\
\hline $\begin{array}{l}\text { Me preocupo em buscar capacitação para o ensino } \\
\text { adequado de alunos com NEE. }\end{array}$ & 0,0 & 0,0 & 11,1 & 40,7 & 48,2 \\
\hline $\begin{array}{l}\text { Não parei ainda para observar se a faculdade que } \\
\text { ensino teria acessibilidade para os deficientes visual e } \\
\text { auditivo. }\end{array}$ & 25,9 & 33,4 & 0,0 & 29,6 & 11,1 \\
\hline $\begin{array}{l}\text { Se hoje eu recebesse um aluno com NEE em minha } \\
\text { aula eu saberia como recepciona-lo didaticamente. }\end{array}$ & 0,0 & 18,5 & 29,6 & 33,4 & 18,5 \\
\hline $\begin{array}{l}\text { Já tive a percepção que eu posso, a qualquer momento, } \\
\text { ter uma deficiência intelectual e/ou física e, também } \\
\text { necessitar de atendimento especial. }\end{array}$ & 7,4 & 7,4 & 11,1 & 29,6 & 44,5 \\
\hline
\end{tabular}

Fonte: Autores, 2018.

O envolvimento dos professores com a prática docência deve ser pautado no comprometimento profissional para a construção de uma educação de qualidade e igualitária, especialmente na contextualização de alunos com NEE nas universidades brasileiras, como na instituição em estudo, onde os docentes ainda necessitam serem mais críticos e ativos em relação a essa temática.

Pesquisas apontam que, apesar da importância das disciplinas sobre a Educação Especial durante a formação acadêmica [15], isso não é suficiente para formar profissionais mais aptos a essa realidade. Os cursos de licenciatura também têm apresentado carência na formação de profissionais aptos a lidar com deficiências como a surdez [12]. Na literatura, alguns pesquisadores [17] reportaram que mais de 40,0\% dos professores entrevistados afirmaram que é uma necessidade que todos os professores possam ter em algum momento capacitação profissional para ensinar a alunos que possuam algum tipo de necessidade especial e, mais de 80,0\% deles acredita que os cursos de capacitação vão contribuir para o exercício da profíssão.

É necessário então que os profissionais sejam conscientes que os alunos com NEE não são incapacitados de exercer atividades, apenas necessitam de formas de inclusão para cada tipo de limitação que a deficiência pode gerar, contribuindo para o ensino igualitário [2].

\section{CONCLUSÃO}

Os professores participantes da pesquisa têm conhecimento sobre a Educação Inclusiva e lecionam disciplinas a alunos que possuem NEE intelectuais e físicas. Eles afirmam buscar metodologias diversas para melhor atender os alunos. Apesar disso, poucos souberam conceituar exemplos de deficiências intelectuais e a maioria nunca percebeu se a instituição que trabalha tem acessibilidade para alunos com deficiência visual ou auditiva.

Muitos professores não têm capacitação profissional para atender alunos com NEE, o que pode refletir numa educação pouco inclusiva. Essa capacitação deve ser parte integrante do plano de ação da política educacional do país, fazendo parte do plano escolar e atividade dos professores. Desta forma, visto que os alunos com NEE tem direto ao ensino com garantia do direito à igualdade de oportunidades de acesso e êxito escolar. 


\section{AGRADECIMENTO}

À Coordenação de Aperfeiçoamento a Pessoal de Nível Superior (CAPES) pela concessão de bolsas de estudos de mestrado.

\section{REFERÊNCIAS BIBLIOGRÁFICAS}

1. Fageria PMF, Camargo D. As Emoções do Professor Frente ao Processo de Inclusão Escolar: uma Revisão Sistemática. Rev Bras Ed Esp. 2018 Abr/Jun;24(2):217-28, doi:10.1590/s141365382418000200005.

2. Aporta AP, Lacerda CBF. Estudo de Caso sobre Atividades Desenvolvidas para um Aluno com Autismo no Ensino Fundamental I. Rev Bras Ed Esp. 2018 Jan/Mar;24(1):45-58, doi:10.1590/s141365382418000100005 .

3. Sousa NA, Silva Junior MF, Costa SK. A ecopedagogia e a educação inclusiva no Projeto Político Pedagógico de escolas de Vitória da Conquista na Bahia. REMEA. 2015 Set;32(1):247-269.

4. Ferrari MALD, Sekkel MC. Educação inclusiva no ensino superior: um novo desafio. Psicol Cienc Prof. 2007;27(4):636-47, doi:10.1590/S1414-98932007000400006.

5. Nozu WCS, Bruno MMG, Cabral LSA. Inclusão no Ensino Superior: políticas e práticas na Universidade Federal da Grande Dourados. Psicol Esc Educ. 2018;22:105-13, doi:10.1590/217535392018056.

6. Barbosa AJG, Conti CF. Formação em psicologia e educação inclusiva: um estudo transversal. Psicol Esc Educ. $2011 \mathrm{Jul} / \mathrm{Dez} ; 15(2): 231-40$, doi:10.1590/S1413-85572011000200005

7. Papi SOG. Desenvolvimento Profissional de Docentes Iniciantes na Educação Especial. Educ Real. 2018 Abr/Jun;43(2):747-70, doi:10.1590/2175-623669053.

8. Campos CJG, Turato ER. A análise de conteúdo em pesquisas que utilizam metodologia clínicoqualitativa: aplicação e perspectivas. Rev Latino-am Enfermagem. 2009 Mar/Abr;17(2):1-6.

9. Brasil. Ministério da Educação, 2008. Política nacional de educação especial na perspectiva da educação inclusiva. Documento elaborado pelo Grupo de Trabalho nomeado pela Portaria n ${ }^{\circ}$ 555/2007, prorrogada pela Portaria nº 948/2007, entregue ao Ministro da Educação em 07 de janeiro de 2008. Brasília.

10. Ferreira MBR. Vertentes da Educação Inclusiva. Pro-Posições. 2018 Jan/Abr;29(1):12-9, doi:10.1590/1980-6248-2016-0128.

11. Bazon FVM, Furlan EGM, Faria PC, Lozano D, Gomes C. Formação de formadores e suas significações para a educação inclusiva. Educ Pesqui. 2018 Jun;44:1-19, doi:10.1590/s16784634201844176672.

12. Ramos DM, Hayashi MCPI. O Lugar da Educação de Surdos nas Dissertações e Teses. Rev Bras Ed Esp. 2018 Abr/Jun;24(2):247-60, doi:10.1590/s1413-65382418000200007.

13. Dorziat A. O profissional da inclusão escolar. Cad. Pesqui. 2013;43(150):986-1003, doi:10.1590/S0100-15742013000300013.

14. Rodrigues D, Lima-Rodrigues L. Formação de professores e inclusão: como se reformam os reformadores?. Educ Rev. 2011 Jul/Set;41:41-60, doi:10.1590/S0104-40602011000300004.

15. Garcia RMC. Política de educação especial na perspectiva inclusiva e a formação docente no Brasil. Rev Bras Edc. 2013 Jan/Mar;18(52):101-19, doi:10.1590/S1413-24782013000100007.

16. Silva CCB, Molero ESS, Roman MD. A Interface entre Saúde e Educação: percepções de educadores sobre educação inclusiva. Psicol Esc Educ. 2016 Jan/Abr;20(1):109-15, doi:10.1590/21753539/2015/0201934.

17. Pasian MS, Mendes EG, Cia F. Atendimento educacional especializado: aspectos da formação do professor. Cad Pesqui. 2017 Jul/Set;47(165):964-81, doi:10.1590/198053144242. 